\title{
Activated H2OPE to Help you Heal: The Mother and Matrix of All Healing
}

\author{
Gunnar V Espedal* \\ Viktor klinikken, Norway
}

Submission: January 04, 2017; Published: March 21, 2017

*Corresponding author: Gunnar V Espedal, Snekkerveien 22, 4321 Sandnes, Norway, Tel: +4798841615; Email: gunnarespedal9@gmail.com

\section{Commentary}

Over the centuries man has wrestled to unravel the mysteries of water. It is clearly the most magnificent element in life, and not just two molecules of hydrogen and one molecule of oxygen, as most assume.

The father of modern bio-chemistry, Albert Szent-Gyorgyi (Nobel Prize Winner) said that:

"Water with its electromagnetic field, is the mother and matrix of all life."

Kahlil Gibran, Lebanon's beloved author and mystic wrote:

"In one drop of water are found all the secrets of all oceans, in one aspect of you are found all aspects of life's existence." An artist and a scientist expressing a holistic view from a different angle. Many other researchers have found that exploring the unknown, an artistic angle may free up the creative potential from within, and we are currently seeing a merging of spirit and science for the better and humanity. Intuitively these two great thinkers understood and described the universe as a holographic reality...

\section{"As above, so below".}

The same Solfeggio frequencies are reproduced in every strand of DNA and also in every grain of sand or dust. From simplicity, divine fractals multiplied and magnified reveal the same repeating pattern. Many fundamental mysteries have been solved and revealed from research done into bio-physics, electro medicine, structured water science, sacred geometry, cymatics, crystal energy and standing wave theory. This has opened up roads to new discoveries around water and its structure and function, and associated inventions. But we should not deceive ourselves into believing that we have solved the mysteries and explained the anomalies of the water. Far from it. We have barely dipped our toes into the vast oceans of knowledge and wisdom in this matter. The search for the meaning of life and its code goes on.
A Norwegian author, Sigbjørn Obstfelder (1866-1900) from my hometown Stavanger put it succinctly in this poem:

Help me, singing light of the day, to find the word, the creating word, help me, night's embracing shade

life's depth to fathom, its mystic code Help me, you loving human eyes to mount on souls to soul's abode.

As I sat reminiscing by one of Norway's most well known fjords, the mystic Lysefjorden with the famous Pulpit Rock, I was transported back in time to the fifties. In the hilly slopes of Eidane, our father revealed to us kids an exhilarating new discovery as he brushed aside the heather hiding the secret: A gushing water well, of fresh mountain water spring. Eyes wide open we asked where the water came from, bubbling up from some where..

"Deep, deep inside the earth, my son, from the earth's cathedral" our father declared in a solemn voice. From an aquifer no less!

Two dumbfounded boys from the town, drank the deliciously fresh, pure and structured water and were miraculously rehydrated and re-energized after a long and physically hard day of work on the steep hills of our childhood's Eldorado.

Two dumbfounded boys from the town, drank the deliciously fresh, pure and structured water and were miraculously rehydrated and re-energized after a long and physically hard day of work on the steep hills of our childhood's Eldorado.

This became my first enlightened encounter with the mystery of water and sixty years later H2OPE, in its grand an unadulterated form still excites me and has been a cornerstone in my quest to find the best possible holistic health solutions for my patients in almost fifty years of clinical practice.

It may have been an ordinary day for the folks working on the farm that day, but for me it was a significant day, an event that triggered me to write "New Lease of Life" and invent a unique 
water generator, which was going to help thousands of people, animal and plant life around the world.

It is strange to think that the great French romantic writer Victor Hugo experienced the same landscape (and it does affect us all, albeit differently) in 1866, when he wrote:

"Nowhere are these frightful and overwhelmingly compound forces more evident than in this strange fjord (Lysefjorden). This is the most fearful and most dreadful fjord arm that exists. Nor is there anywhere else where the secret interplay between elements more complete. Here, in the middle of this great wasteland, enters a gloomy street. A no- man's land. Where is the wind? Not in the sky. The wind is in the sea, the thunder is in the mountains, not in the sky. Sometimes the water is shaken as if there is an underground earthquake. Sometimes thunder can be heard without a cloud in the sky. All of a sudden a luminous ray shoots from the mountain walls and retracts like a boomerang, then shoots out again. One mountain attacks another. Bombardments in the walls of the mountains. It is the hate between the cliffs abyss striking yet again" (Toilers of the Sea).

Maybe the great writer was dehydrated and depressed? The death by drowning of his daughter Leopoldine Koreles and her husband in 1843 and his own exile in Guerncey and later Jersey for nineteen years, may have accounted for his gloomy outlook on life.

Energy medicine to the rescue! Restructured water does rehydrate much faster and more effectively than any other kind of water or fluid, and will restore cellular activity and DNA regeneration. Plus, Bach flower remedies, which of course is another type of energy medicine.

The curative powers of water are not only for the soul, but also for bodily ailments.

The mythology of the fountain of external youth as water's most potent power of regeneration, is also connected to countering specific maladies. According to the practical wisdom of Atharva Veda, water has healing powers that drive away diseases and also has creative capacity. Holy wells and springs embody water's divine life- giving and life preserving qualities. The human eye is also metaphorically associated with water. This is beautifully described in Henry Thoreau's book 'Walden'. In his description of lakes as a landscape's most wonderful and expressive feature:

" A lake is the earth's eye, looking into which the beholder measures the depth of his own nature. The trees by the lakeside are its eyelashes, the wooded hills the brows. In freezing winter, it closes its eyelids to become dormant for three months or more"

\section{The River Thames and the Healing Water}

Eye disease (ocular ailments) and its connection with water led Peter Ackroyd to prescribe the River Thames, along with the 26 healing springs found in the vicinity, which resulted in the practice of healing for the eyes being viewed more credibly.
Glaucoma is popularly known as "water of the eyes". The disease is caused by increased pressure within the eyeball as a result of blockage of fluid. The word shares its etymological roots with Glaucus, one of the Greek sea-gods. "Glaucus" means bluish-green, the color of the sea. The tradition of eye-healing goes back to the time of Augustine's miracles near the river at Crickload, where he enabled the blind to see, as well as the ophthalmological marvels attributed to the 7 th century princess Frideswide at the well at Binsey, near Oxford. This was the well that was transformed in Lewis Caroll's Alice in Wonderland. "Treacle well", an old term derived from Latin thermic, meaning medicine or antidote to poison.

Is it not interesting that the London Eye, situated next to the River Thames, is the world's most visited tourist attraction, in the context of eye healing and the 26 healing springs found in the vicinity?

Many natural healing waters exist today and Lourdes being the most famous.

Professor Esther Stenberg, USA claims that 30-90\% of the effects seen at Lourdes is attributed to faith and confidence in the water and its holistic environment. Compassion. Altruistic love, the opening of the heart, smile. Empathy will relieve the body of stress and open the body's self healing capacity, through the body, heart and mind connections. Health supporting hormones and enzyme systems are stimulated and balanced. An overall wellness feeling will ensue as a result of all these factors.

But with the new research done by Professor Luc Montagner (Nobel Prize Winner), Dr. M. Emotu, and Dr. J. Beneviste there maybe other explanations at work here. Structured, hexagonal water can easily carry energy imprints documented in various tests (fast freezing, Hagalis test, GDV, gas discharge visualization). Structured water can carry and transfer energy waves and imprints as a "memory". This fact has led many to ridicule and dismiss this scientific work as nonsense with critics and scorn at every corner. But the work of Prof Ling and Pollack, and many others, shows that this field is advancing in the new knowledge of structured water.

\section{Poisons in our Drinking Water}

When the abysmal facts on the sad state of our drinking water is presented, everybody will agree that it is far cry from a healthy and life-supporting quality it once was. That is, in a pure, structured and energy-rich state. Living in ignorance and defending public water supply till the end are the official water authorities and their governing bodies. What about all the chlorine and by-products, heavy metals like lead, cadmium, arsenic, herbicides, pesticides, hormone-mimicking material (Xeno-oestrogen), aluminium, radio active pollution etc. that contaminate our water every day?

People have been deceived and myths are propagated: In Norway we are led to believe we have "the world's best drinking water", despite old and seriously leaking water pipes (some of 
the worst in Europe). Most of our drinking water comes from surface water. Humus is formed by the natural breakdown of plants, soil and animals, forming humic and fulvic acids. When chlorine is used for disinfection purposes, dangerous chlorine products, such as tri-halomethanes are formed, shown to be carcinogenic, class B (animal studies).

Over the last decades, we have witnessed an ever-increasing amount of pollution in our eco-system. Several species of fish and mammals have changed sex and children aged 4 have fully developed breasts, caused by pesticides used in agriculture.

Our water reservoir, no matter where you live, is badly affected by the increased amount of pollution, as we are all part of the same eco-system and hydrological cycle. During heavy rainfall, as we have had this summer in parts of Norway, together with the melting of snow in the spring, more chemicals are flooded into our drinking systems, especially aluminium (linked to Alzheimer). Measurements performed by Prof. J. Vogt at University of Oslo tell us that never before have they seen such high levels of aluminium in our drinking water.

In the early seventies a noticeable change was observed in our environment as acid rain from UK and the Continent turned many lakes and rivers into hostile environments for fish. The effect was felt greatest in the south and south west of Norway (Closest to UK and the Continent) and millions of trout and salmon died as a result. Rain is slightly acidic, but when mixed with industrial pollution such as Sulphur oxide, nitrogen oxide and associated carbons it reacts in the air with sunlight and water to form nitric acid, sulphuric acid, ammonium salts and other assorted mineral acids. In Greece, the rain lands on the rocks from which it is made, dissolving the famous Acropolis and Pantheon in Rome. Some improvements were achieved by disposing vast quantities of limestone rocks into the lakes and rivers to counteract some of the acidity.

We have all been deceived and lied to regarding our drinking water. The toxic pollution of our planet is reflected in the worlds drinking water as well as the oceans. We are faced with an unprecedented loss of species comparable to the great mass extinctions of pre-history.

Dr. Alex Rogers, Professor of Conservation Biology at Oxford University, has said that these findings are shocking and worse than the most pessimistic predictions, and our drinking water is no exception. But there is a consolation and a rescue at hand: $\mathrm{New}$ technology and unique water devices being built on the frequency resonance principle. It is naive to think that the governments and water authorities will move to take the rightful and much needed action. EU has criticized Norway's old and leaking water pipe system, often lying parallel to leaking sewage pipes with disease causing microbes resistant to chlorine disinfection. Conservative estimates tell us it will take about 200 years to change the water pipe system at the rate it is going at the moment!
In 2004, Giardia Intestinalis, a water borne parasite, resistant to chlorine, caused 1500 people in Bergen to become seriously ill. Around 200 of them developed M.E (Chronic Fatigue Syndrome) and more than 500 compensation cases have been in the courts, as the Bergen council was held responsible for this water scandal. It could all been prevented.

Luckily most European countries do not have fluoride in their drinking water.

How could a very toxic by-product of the aluminium industry be allowed in the drinking water?

To understand this, we have to examine the money trail, manipulation of data and its close connection to the nuclear industry and the development of the atomic bomb.

\section{The Dangers of Fluorides}

As this element is often added to drinking water, let us examine the validity of this assumption. Long before any health security tests were carried out, fluoride, a derivate from the aluminium industry, was introduced into the drinking water in some countries. How could a toxic by-product of aluminium be allowed into the US's drinking water?

To understand this, one has to examine the industry's money trail, manipulation of data, and its close connection to the nuclear industry and development of the atomic bomb.

It is well documented that data was manipulated in the Newburgh-Kingston Caries Fluorine Study. Recent declassified documents demonstrated the pro-flour stance by the Public Health Service and The Manhattan Project, during the development of the atomic bomb. It is correct to say that The Manhattan Project sold and recommended fluoride to the American people.

On the other side of the Atlantic Ocean in Copenhagen, Denmark, from 1920-30, a group of world-renowned scientists headed by Niels Bohr were working on the groundwork for nuclear fission. In this environment worked a brilliant and courageous scientist called Kaj Eli Roholm, who paved the way for a proper understanding of the dangers associated with fluoride.

Almost all the world's supply of fluoride came at that time from a large deposit of cryolite in a site in Greenland, which belongs to Denmark. Cryolite is a word of Eskimo origin, meaning ice stone. Researchers discovered that aluminium could be more easily extracted by melting the ice stone together with bauxite. These metals where used extensively during the First World War. The factories where these metals were used were heavily polluted and workers became very ill with many diseases such as crippled backs, so-called 'poker back', cancer, osteoporosis, and lung diseases. Kaj Eli Roholm pointed out the cause of these diseases: fluorine intoxication. 


\section{Journal of Complementary Medicine \& Alternative Healthcare}

\section{Fluoride in our Drinking Water-History and Science}

You have probably heard that fluoride is necessary to prevent caries in the teeth and that fluoride-containing toothpaste and tablets should be used for that reason. The brilliant scientist Kaj Eli Roholm came to the opposite conclusion, however: he says that there is no scientific evidence that fluoride prevents caries (tooth decay), and will in fact damage dental enamel! His warning came 70 years ago. Studies conducted on both humans and sheep confirmed these findings. In Iceland, sheep became ill with bad teeth and crippled deformities, especially with gaddur, when volcanic ashes containing fluoride poisoned the fields in which the sheep grazed. Dental fluorosis (Colorado Brown Stain or Texas Teeth) is an indication of systemic fluoride poisoning which originates from drinking groundwater polluted by fluoride.

At the time of Kaj Eli Roholm's findings, several new industries were started up based on the properties of fluoride; for example, the production of carbon-based fluoride products and Freon in refrigerators. During the Industrial Revolution, thick clouds of smog hung over Europe. In the early seventies, when I studied physiotherapy in Bradford, Yorkshire, the renovation of the region's black buildings had already started. But whilst most researchers came to the conclusion that sulphur compounds were the main cause of this black pollution, Kaj E. Roholm concluded that it was fluoride, not sulphur, that was the culprit and the real danger in pollution.

The past century's biggest industrial scandal occurred in the Meuse Valley in Belgium where 60 people were killed and several thousand injured in 1930 as a result of fluoride poisoning-not sulphur. Kaj E. Roholm studied the new global aluminium industry and its pollution in Switzerland, Italy and Norway. Commonly observed diseases in these factories were osteoporosis, asthma, headache, nausea, intestinal pain and diarrhoea. The work of A.W. Frostad published in the Norwegian Medical Publication (Vol. 56 p.179 in 1936) stated that fluoride intoxication in Norwegian aluminium workers was the main cause of asthma and pulmonary disorders (occupational hazard).

In 1937, Kaj E Roholm published 364 pages of documentation called Fluoride Intoxication. Translated into English, it contains 893 scientific references-a monumental works blasting like Danish dynamite, shaking the very foundations of the cryolite, aluminium and fluoride industries worldwide.

With the onset of World War II, the production of fluorine compounds increased dramatically to meet warfare needs, especially in developing the world's first atomic bomb, under the auspices of research and development project The Manhattan Project. Security requirements kept most information about the use of fluoride and its health hazards a secret during the war and many years afterwards.

\section{Fluoride in our Drinking Water-More Rotten Eggs in the Basket}

Based on data, which was deliberately manipulated and hidden, US became the first country to allow fluoride in its drinking water. Sweden was one of the first European countries to fluoridate its water supply in 1952, but this practice was finally prohibited by Sweden's Parliament in 1971. Industries in China and Australia removed some of the arsenic lead and other toxins from the industry and placed it in the water distribution network in greater parts of Australia. The industry saves a lot of money, and citizens are slowly being poisoned, led to believe that it is fluoride in the drinking water that is the cause of the pollution.

Ann Bessington, an independent member of the parliament in Australia, has documented the fact that many toxins, including fluoride and aluminium, pollute the drinking water of the City of Adelaide. The drinking water is destroyed, dead and chemically treated by toxic substances. Fluoride is the main ingredient in rat poison, sarin gas and Prozac (anti-depressant)

As we have seen, fluoridation of drinking water can result in serious damage to health, such as osteoporosis, cancer, and disturbances in brain, liver and kidneys function. The truth about the seriousness of these facts had so far been hidden through corruption and manipulation by the industry and organisations, including health authorities in several countries. The serious and dangerous practice of adding fluoride to drinking water has existed since 1930. Today, it exists in many guises, such as PFC (per fluorinated compounds). Hitler and Stalin used fluoride in concentration camps and gulags to mass-control people, rendering them docile.

About 50 years after the scandal of Newburgh, another source of fluoride's damaging effects is per fluorinated compounds (PFCs). As with fluoride in toothpaste, PFC is present in many household brands, such as Teflon, Gore-Tex and Stainmaster (stain removal agent), and hundreds of others. The truth about the damaging effects of PFCs is hidden or ridiculed by the proponents of this industry-just as with fluoride in 1930 .

The truth about fluoride and all its toxic derivatives passes through three different stages, as first described by the German philosopher Arthur Schopenhauer 200 years ago. First, it is ridiculed, before it is strongly antagonised, and finally the truth is accepted as self-evident.

When it comes to fluoride in drinking water, I believe we are currently in stage three; hopefully, it is only a question of time before this dangerous practice (i.e., forced intoxication of whole nations and their citizens) ceases. Fluoride is a known neurological toxin, which is biologically active and accumulates in body tissues, interfering with the enzyme systems, damaging the hormonal system and weakening the immune system, leading to neurological diseases. Several hundred scientific studies exist 
documenting this fact. Twenty-five of these studies show that children achieve a significantly lower IQ when using fluoride.

The chemical industrial giant Du Pont is the leading producer of organic fluorides. Through The Manhattan Project, uranium hexafluoride was used to develop the atomic bomb. After the war, the market was flooded with products based on fluorocarbons: plastic, pharmaceuticals, spray, pesticides, household cleaning materials, et cetera. By the end of the 20th century, millions of tons of CFC and DFC had polluted the atmosphere, our blood and other body systems. In 1966, Theo Colborn, John Peterson Myers and Dianne Dumanoski published the book Our Stolen Future. This is an investigation into the disturbances and damage done to the hormone and immune systems throughout our lifetime. The book is one of the clearest warnings in existence today about the health and environment threat that these chemicals representbut, strangely enough, it contains not a single reference to PFC. Many scientists were quite embarrassed that this class of chemicals had escaped the scrutinising radar of environmental science for almost 60 years. Data on the damaging effects of these chemicals existed, but was not published in the scientific forums until quite recently. The conclusion is that PFC is very durable and lasts a long time in the environment. Fluoride from these sources can be absorbed from carpets, furniture, Teflon, household products, et cetera. Fluoride gradually accumulates in core regions of the brain that govern behaviour, notably the hippocampus and the limbic areas, resulting in hyperactivity or the opposite: apathetic, lethargic behaviour. More than 124 studies carried out on laboratory animals have confirmed these facts.

For over 70 years now, fluoride has been used in household products and water for cooking. Today, one out of ten children is diagnosed with ADD/ADHD, and the numbers are rising rapidly. Alzheimer's, Chronic Fatigue Syndrome, hypothyroidism, arthritis and autism spectrum disorders are all on the rise, and environmental pollution is partly due to fluoride, heavy metals like mercury in dental fillings and vaccination (thimerosal), CFS, PFC. Many environmental organisations are working diligently to implement a ban on fluoride in drinking water. Prof. Paul Connett, a specialist in environmental medicine and member of the Fluoride Action Network, is one of the leading activists in this area.

Fluoride is derived from aluminium, a toxic element for which there are strict rules and regulations on handling and storage. Is it not senseless to allow poisonous fluoride sludge from the aluminium industry into our water, toothpaste and other household products?

\section{The Emperor's not Wearing Any Clothes!}

Dr. John R. Lee, a medical doctor, researcher and author who also became a personal friend when I invited him to Norway and we did a Scandinavian tour to put osteoporosis and natural progesterone firmly on the map. In between lecturing and playing basketball with our kids, he told me many interesting stories, but the one about fluoride has stuck with me. He told me how he had been indoctrinated at medical school to believe that fluoride helps prevent tooth decay. But his thorough and independent investigation into the science of fluoridation, its effectiveness and safety found that 'the Emperor's not wearing any clothes'.

He could not find any evidence of fluoride effectiveness and safety. He even conducted his own very thorough doubleblind study in this field. The results were dramatic and clear: regardless of the patients' ailments, they all got worse when drinking fluoridated water, and when drinking non-fluoridated water, their conditions improved, less osteoporosis, hip fractures and cancer. Check out the excellent article by dr. John R. Lee, MD, "The Fluoridation Scam. The selling of Fluoridation in America. "There is even a file directory, stop Fluoride Poisoning, which includes EPA whistle-blowers. http://www. net-fluoride/filelist$\mathrm{htm}$. World famous neurosurgeon Russell Blaylock, MD, says in his book "Health and nutrition secrets to save your life" that only the light of truth can halt this process". (www.blaylockmd.com).

Carefully conducted studies conclusively that fluoride weakens the bone structure, causing an increase of hip fractures in men by $41 \%$ and in women $27 \%$ (Utah Mormon Study). Fluoride will also damage the brain and the nerve system, especially the developing brain in pregnant women and small children.

Once the majority of our food and water supplies are contaminated along with the soils, everybody will be affected by hazard of fluoride toxicity, (A compounding effect). Drinks packaged in aluminium cans and bottles, i.e.: diet drinks, sodas, fruit juice, bear and energy drinks are the worst. The most toxic brain aluminium fluoride with multiple toxins found in aspartame, sucralose, Splenda, NutraSweet etc., creating the most powerful government approved toxic cocktail imaginable. According to a study done of the University of Oslo, Norway. The measurement of aluminium levels in the drinking water has never been higher than today. And it is steadily increasing.

"We cannot solve our problems with the same level of thinking we used when we created them"

\section{-Albert Einstein.}

The hidden toxins lurking in your water, air, food and environment and how you can avoid them, regain your health and vitality is laid out in the book New Lease of Life.

Mike Adams has just released a new book called Food Forensic, a very important book of extensive research into toxins like polysorbate 80 , MSG, sodium nitrite, pesticides and weed killers like glyphosate (Round-up) and how to prevent and 
remove them from our household. Through his ISO-accredited analytical laboratory he has documented the wide spread content of health damaging ingredients in our daily food.

As far as water is concerned it is important to install a water filtration system. Never drink water direct from the tap as it includes, as we have seen many toxins and chemicals added to the municipal water. According to the laboratory tests done by Mike Adams, The Big Berkey (with Fluoride filters) and Zen Water Systems removed most of the heavy metal toxic compounds. For countertop water filters, the Zero water brand came out on top. Reverse osmosis will also remove toxic heavy metals. All the results are published on www.waterfilterlabs.com.

Others are formed in the water pipes on the way to the consumer. As it is pumped in straight pipelines under pressure, this will ruin water's structure and vitality. Therefore, a water generator which can restructure the water electromagnetically is advisable.

Vital water in nature possesses a coherent structure as it moves in spiral formation (vortex). Because of the piezoelectric properties found in nature, energy is transferred to each water molecule. Circulating water in vortexes picks up energy from light and sound. All this and more adds up to what is called vital, living water.

Crystal-shaped, hexagonal clustered water molecules form the matrix of healthy DNA in the body. These specific types of molecules are capable of receiving and transmitting electromagnetic signals: Photo-phonon emission of intercellular communications. Today, due to aging and the ever-increasing amount of toxification due to stress and environmental pollution, these supportive water clusters are disturbed and malfunctioning.

According to Dr. Lee Lorenzen, one of the world's leading experts in water technology, this is the primary underlying reason for aging and disease.

When vital, clustered water with hexagonal structures is consumed, a high frequency wave of information is transmitted to the proteins. This is a kind of "wake-up call" for a wave formation to restore normal cell function (homeostasis). Almost imperceptible electromagnetic signals have the power to influence your whole body by supporting and activating the DNA system.

It is interesting that the "tree of life", DNA's so-called double helix, has clustered water molecules supporting this structure reminiscent of ancient and modern Sumerian art depicting the two intertwined serpents, the symbol of medicine and healing today, emulating the structure of the genetic code.

The scientific evidence in this field is measured using $\mathrm{Ph}$, ORP meters for redox potential, infrared spectroscopy, nuclear magnetic resonance, GDV scanning (electro-photonic analysis ad modem Prof. K. Korotkov, dark field microscopy, Hagalis test (A
Swiss laboratory test) showing the structural changes and many more clinical tests like kinesiology, pulse testing, BMI. Heart Rate Variability (HRV test) and many more.

The scoffers of this innovative technology are dangerous carriers of false knowledge, and if not recognized for what it is worth, it will delude and poison you and deceive you no end as the following story will illustrate.

Almost three years ago I had the opportunity to lead a small team of researchers and inventors of new water technology. Pure Norwegian, a water generator, is quite different from other water devices as it does not use magnets, battery, electricity or filter of any kind. Other electromagnetic devices often consist of electromagnets or electrical coils and rely on an external power source.

The device is attached to the cold water pipe and when the water is flowing, the vibratory, kinetic energy is picked up by a receiver unit inside the device. Various metals are in an ordered sequence, chosen carefully in regards to resonance properties. An oscillating wave is amplified and transported to a broadcasting unit making use of the piezo electric effect from various crystals. The signals are propagated through space and material. A bachelor thesis at University of Stavanger was written by Elina Alvsvåg under the supervision of Professor Malcolm Kelland.

The various theories were narrowed down to three:

1. Influence on the structure of the water.

2. Influence on the ions of salts in the water (Lorenz force)

3. Influence on colloidal particles.

The most significant point is evaluated to be zeta potential changes. This phenomenon connects the theories about Lorenz force, colloidal particles and the hydration structure under one mechanism. The Lorenz force affects the colloidal particles being magnetic, non-magnetic and calcium carbonate as well, resulting in a reduction in zeta potential, which further give modifications to the hydration layer and therefore the structural hydration of the particle.

Having tested the device at the Hagalis Laboratory in Switzerland and got verification of totally altered molecular water structure compared to municipal water from the same source under same testing condition. See the following illustration. Municipal, tap water: The structure consists of rigid right angled lines indicated no energy or "dead" water. With the new invention attached to the water pipes, an immediate change of structure is seen: Snow-like crystal formation indicating pure, restructured and energetic living water.

Field testing: Animals, such as dogs and cats always chose the water from Pure Norwegian water device as seen when you put two bowls of water on the floor, one with ordinary tap water, the other with restructured, healthy water. 
Pig farmers: Many pig farmers have stress related problems with their pigs, often resulting in aggressive behavior and tail biting, which can lead to infections, antibiotics and sometimes early death. By installing Pure Norwegian Water device this problem has been greatly diminished and eliminated, as the pigs are calmer, less stressed due to highest quality water. Better hydration and a calmative effect is observed.

Private households: Elimination of smell and bad tasting water is observed immediately which indicates that something positive has happened to the water. Clients who used to boil their water, have stopped doing so because of the new freshness of the water. Metallic taste and discoloration is reduced and sometimes eliminated completely.

Clients report back on a much smoother and silkier water and no need to use moisturizing lotions anymore.

Significantly reduced use of chlorine in swimming pools.

Anti-scaling effect. Testimonials of significantly less or no scaling seen where hard water is an issue. Especially seen in valves, hoses, pumps in industry and golf courses.

Plants grow faster and become lusher. Increased Brick measurements which indicates higher than normal nutrient density.

As an integrative holistic practitioner for almost fifty years, nothing brings me more joy than hearing happy testimonials from clients who have first hand experienced the health benefits and restructured water with more oxygen and hydrogen.

A lady came to our clinic and told us how she had suffered from intense pain daily for almost 20 years and could hardly walk. Because of an under active thyroid gland, she lacked energy and was constantly cold on her feet and hands. Her sleep was very erratic and using two duvets at night told me her life was pretty miserable. In addition to that she took about 200 painkillers a month just to survive.

After three weeks she came back, beaming with happiness: Pain-free, going for long walks and sleeping well with no medication. Even a kidney problem had resolved, according to her doctor who was amazed at the healing transformation.
The two kind of waters are like day and night. Restructured water, slightly alkaline with enriched oxygen and hydrogen and negative ions detoxifies and furnish the body with the best possible self healing capacity.

When a representative of the water authorities got wind of the new Pure Norwegian Water generator, a simple scheme of sabotage was set up. A newspaper debate about the bad municipal water was abruptly stopped and a grant for further research was withdrawn. Telephone harassment and ridicule followed.

Experience has shown me that new innovation and truth passes through three stages:

First it is ridiculed, second it is violently opposed. Third, it is being accepted as self-evident. (Arthur Schopenhauer).

"There is nothing new under the sun", as the saying goes.

Throughout all these years in caring curing and helping the sick I have seen that new ideas are met with ignorance, resistance and ridicule:

Acupuncture in the seventies, electro-medicine, Dr. Voll's electro-dermal testing, Dr. John R. Lee on natural progesterone, Professor K. Kahn's immunotherapy, alternative solutions to vaccines, oxygen therapy. Rife technology and innovative research and inventions in water technology.

The new technology will become an accepted household item as a most valuable asset for maintaining total balance on a cellular level, enhancing the efficiency of the immune system and preventing the lifestyle diseases that are so prevalent in society today.

\section{Written by: Gunnar Espedal}

Bio: Gunnar V Espedal is an award winning physiotherapist and naturopath, holistic medicine researcher \& lecturer, trainer, inventor, writer and entrepreneur.

Having successfully treated and attended to over 100,000 patients worldwide, this award-winning therapist has seen the whole aspect of holistic medicine, and still keen to learn and share. Web link: http://gunnarespedal.com

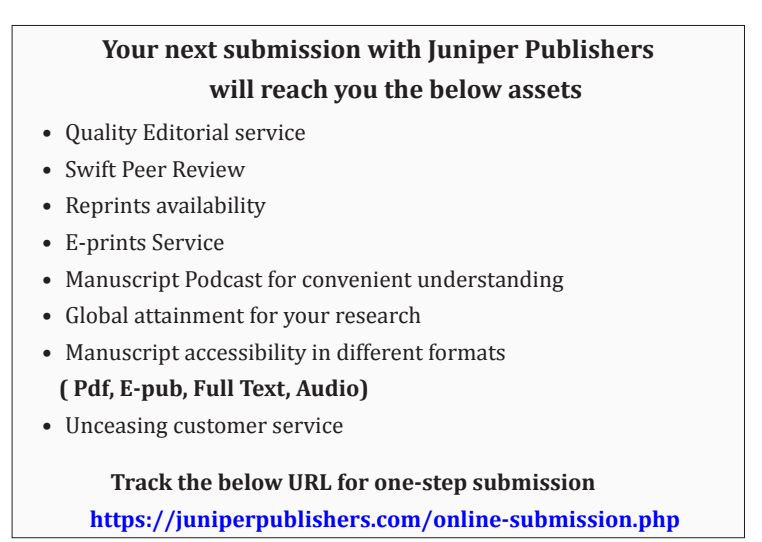

